\title{
EVALUATION OF METABOLIC SYNDROME AND OBESITY IN WOMEN WITH BREAST CANCER TREATED IN A SERVICE WITH INTERDISCIPLINARY ATTENTION. A PROSPECTIVE COHORT
}

Vanildo Prado', Daniel Araújo Brito Buttros¹, Eduardo Carvalho Pessoa', Heloísa Maria Lucca Vespoli, Eliana Aguiar Petri Nahás'

${ }^{1}$ Universidade Estadual Paulista - Botucatu (SP), Brazil.

Introduction: Patients with breast cancer have a higher risk of gaining weight and of presenting with metabolic syndrome (MS), with worsening overall and specific survival. Intervention from an interdisciplinary team can influence the prognosis. Objective: To evaluate the occurrence of metabolic syndrome and its components in women during the first year after diagnosis of breast cancer. Methods: Prospective, single-centered clinical study that included women with a recent diagnosis of breast cancer, age $\geq 40$ years, histological diagnosis of breast cancer, without metastatic disease and without established cardiovascular disease (CVD). Clinical and anthropometric data (blood pressure, body mass index [BMI] and waist circumference) were collected through interviews and physical examination. For biochemical analysis, HDL, triglycerides (TG) and glucose were requested. Women with MS were considered to have three or more diagnostic criteria: waist circumference $(\mathrm{WC})>88 \mathrm{~cm} ; \mathrm{TG}^{3} 150 \mathrm{mg} / \mathrm{dL}$; HDL $<50 \mathrm{mg} / \mathrm{dL}$; blood pressure ${ }^{3} 130 / 85 \mathrm{mmHg}$; glucose ${ }^{3} 100 \mathrm{mg} / \mathrm{dL}$. The measurements were carried out in three moments: first cancerconsultation (T0m), six months (T6m) and 12 months (T12m). The patients underwent interdisciplinary evaluation and monitoring (nutritional and psychological), according to the service's routine. For statistical analysis, the McNemar test was used to compare the moments and the $\chi^{2}$ test of trend. Results: Seventy two women with breast cancer were included, with a mean age of $58.4 \pm 10.7$ years and $83.3 \%$ in the post-menopause. The cancer profile of the patients was that of an early-stage disease ( $94.4 \%$ stage I and II) with a favorable immunohistochemical profile (79.1\% positive estrogen receptor, $72.2 \%$ positive progesterone receptor and $86.1 \%$ HER2 negative). In the assessment of MS, no differences were observed in the occurrence between the three moments, with $37.5 \%$ of patients with MS at diagnosis, $43 \%$ at 6 months and $44.4 \%$ at 12 months ( $\mathrm{p}=0.332$ ). A significant difference was observed in the occurrence of hypertriglyceridemia $\left(\mathrm{TG}^{3} 150 \mathrm{mg} / \mathrm{dL}\right.$ ) of $25 \%$ in T0m, 36.1\% in T6m and $44.4 \%$ in $\mathrm{T} 12 \mathrm{~m}$ ( $\mathrm{p}<0.05)$. There was no increase in obesity criteria $\left(\mathrm{BMI}^{3} 30 \mathrm{mg} / \mathrm{m}^{2}\right.$ and waist circumference / WC $\left.>88 \mathrm{~cm}\right)$ in the studied period, with mean BMI of $28.9 \mathrm{~kg} / \mathrm{m}^{2}, 28.8 \mathrm{~kg} / \mathrm{m}^{2}$ and $28.8 \mathrm{~kg} / \mathrm{m}^{2}$ and WC equal $97.2 \mathrm{~cm}, 97.2 \mathrm{~cm}$ and $96.7 \mathrm{~cm}$, at T0, T6 and T12 moments, respectively ( $>0.05$ ). When comparing the individual MS criteria between the three assessment moments, there was only a statistical difference in the triglyceride and glycemia criteria. The analysis of glycemia showed a decrease in mean values, from $106.6 \mathrm{mg} / \mathrm{dL}$ in T0m, $100.4 \mathrm{mg} / \mathrm{dL}$ in T6m and $98.9 \mathrm{mg} / \mathrm{dL}$ in T12m (p=0.004). Regarding TG, an increase in mean values was observed, from $121 \mathrm{mg} / \mathrm{dL}$ in T0m, $139.4 \mathrm{mg} / \mathrm{dL}$ in T6m and 148.4 mg/dL in $\mathrm{T} 12 \mathrm{~m}$ ( $\mathrm{p}=0.003)$. Conclusion: Women with breast cancer submitted to interdisciplinary evaluation did not show an increase in the occurrence of MS during the first year after cancer diagnosis. Among the components of MS, there was a reduction in blood glucose values and an increase in triglyceride values. 